\title{
JOB STRESSORS AND SLOW MEDICINE IN HEALTH CARE: A SCOPING REVIEW
}

\author{
Bruce Kirkcaldy ${ }^{1} \&$ James Athanasou ${ }^{2}$ \\ ${ }^{1}$ International Centre for the Study of Occupational and Mental Health, Dusseldorf, Germany \\ ${ }^{2}$ Faculty of Health Sciences, University of Sydney, Australia
}

received: 2.8.2018;

revised: 22.10.2018;

accepted: 29.10 .2018

\section{SUMMARY}

This paper provides a framework for addressing the stressors in modern medical health care, especially those that relate to psychology and psychiatry. Despite its advances, organized medicine is beset with inefficiencies and imperfections. The extent of burnout and stress for health professionals is documented in this scoping review. The impact on mental health is described and an approach based on a slower medicine is advocated.

Key words: burnout - stress - slow medicine - health care - health professionals

\section{INTRODUCTION}

Advances in health care have resulted in lower levels of disease, reduced overall mortality and increased life expectancy in the developed world (Hederos et al. 2018). Despite such progress there are reservations about the quality of modern health systems. Key areas where inadequacy had been documented include: (a) errors or failures in diagnosis or failure to treat effectively (Leape 1994); (b) risk assessment and safety (Felton \& Stickley 2017); (c) poor communication (Eliacin et al. 2018); (d) dignity and human rights especially in times of illness and vulnerability (Allard et al. 2018); and (e) provision of aftercare treatment (Behrens 2018).

The purpose of this paper is to indicate how modern health systems have induced individual stress and produced systemic inadequacy. In brief, it is argued that there is an increasing tendency for complex changes in health administration to be counterproductive in promoting more effective health care and at the same time may also be detrimental for the health of the purveyors of medical care, that is, the medical and allied professionals.

For instance, psychiatrists and psychotherapists are likely to experience tension through "underfunding for services, new practice patterns, turf wars, demands for proof of value of services, bureaucratic hassles, and moral dilemmas" (Fleischer 2003). The pervasive stressors involved in clinical practice stretch human capabilities. This is the case where a large volume of administration interacts with complexity or uncertainty to stretch human cognitive resources. A simple example is the introduction of the electronic health record, which has been described almost universally as overlaying medicine with administration and an "interference to be managed..." (Epstein 2017). Hamel and Zanini (2017) outlined the costs of an excessive bureaucracy that is destroying value, slowing production and creating barriers. Their emphasis was lost economic output and they categorised the costs into seven categories of organisational bloating, friction, insularity, disempowerment, risk aversion, inertia or politics.

\section{BUREAUCRACY AND INADEQUACY IN HEALTH CARE}

The increasing bureaucracy in medicine was graphically documented by Sweet (2017) in her narrative account "Slow Medicine". Less time is taken in the care of the patient and more time is spent by professionals in entering data and information (2017, p. 9). She described it as "medicine without a soul" (p. 8) in which reductionism prevails and patients are deconstructed into myriad details. As far back as 1999, Lown expressed concern that medicine has indulged in a Faustian bargain.

A three thousand year tradition, which bonded doctor and patient in a special affinity of trust, is being traded for a new type of relationship. Healing is replaced with treating, care is supplanted by managing, and the art of listening is taken over by technological procedures. Doctors no longer minister to a distinctive person but concern themselves with fragmented, malfunctioning biological parts. The distressed person is frequently absent from the transaction (p.xiv).

The long-term cost of such bureaucracy is not obvious. The first consequence is inadequacy of health care. Over a five-year period, Javanparast et al. (2018) interviewed primary health care services in Australia and noted a rapid re-structuring of health systems based on administrative goals, conflict between medical priorities and organisational changes and poor change management procedures. 


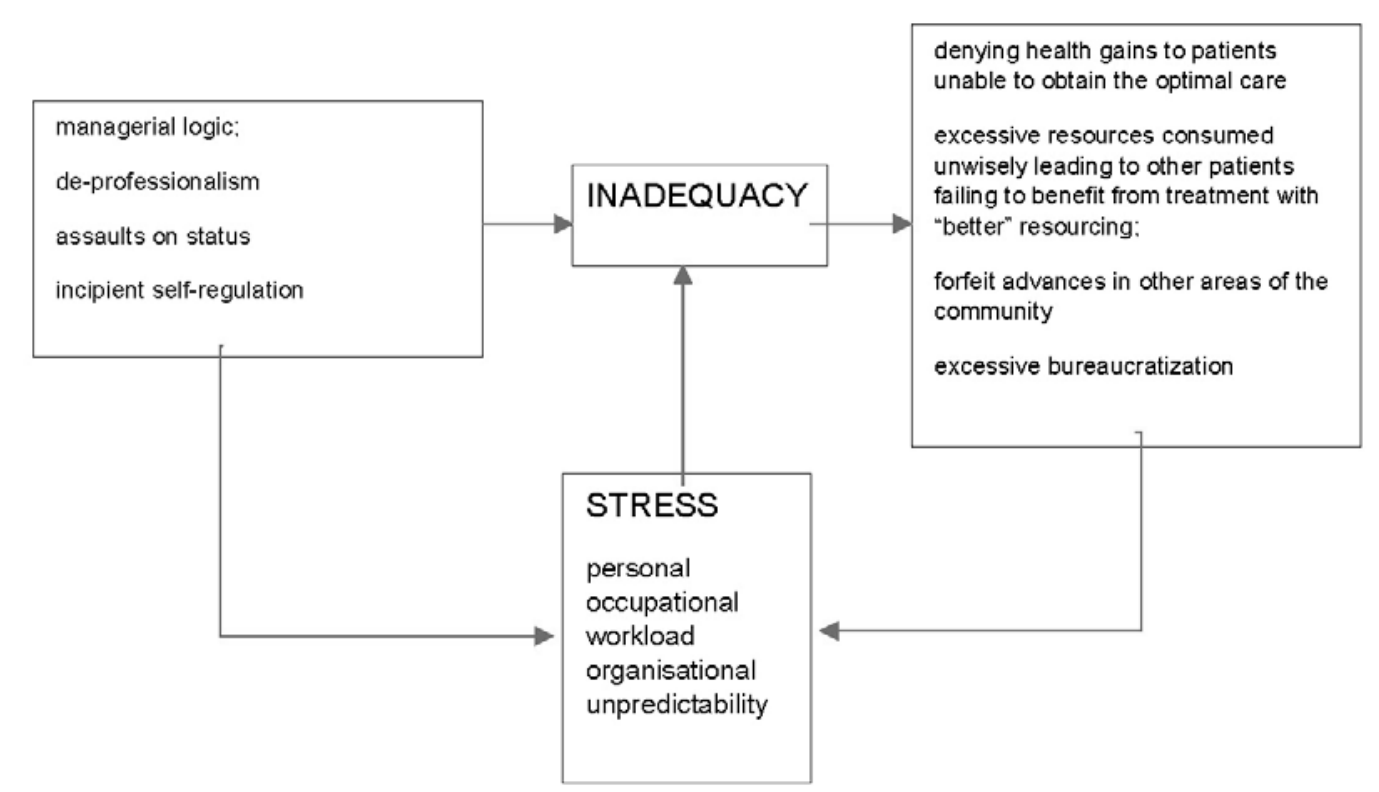

Figure 1. A stress-inadequacy feedback loop arising from bureaucratisation in health care

Potential causes of inadequacy (Hill 2015) have included: (a) decision-making governed by financial, bureaucratic or managerial logic; (b) de-professionalism as a result of non-essential managerial and political control; (c) symbolic assaults on status; and (d) incipient self-regulation (see Figure 1 for an outline of a bureaucracy-inadequacy-stress loop). These developments inevitably adversely affect patient care and the sustainability of a service. As a consequence, less efficient health care is now evident in (a) denying health gains to patients unable to obtain the optimal care within the limited resources; (b) excessive resources consumed unwisely leading to other patients failing to benefit from treatment with "better" resourcing; (c) wasteful implementation that forfeit advances in other areas of the community (e.g., economy, education, welfare, public health); and (d) excessive bureaucratization (Cylus et al. 2016). A key component of the bureaucracy-inadequacy-stress feedback loop is the stress component and this aspect is covered in the scoping review of the next section.

\section{STRESS IMPOSED ON HEALTH PROFESSIONALS}

The stress imposed on health professionals has been located in specific sources. Kirkcaldy et al. (2000) implemented a repertory grid analysis to examine sources of occupational stressors among medical and paramedical health professionals. The core features extracted included the personal context (family situation), the occupational status (physician vs. assistant vs. paramedical), form of social organisation (relationship with co-workers and/or boss), working conditions (salary, vacation, provisions, etc), excessive workload, physical dangers (risk of infections and disease), and unpredictable events (time pressures and unanticipated interruptions).
The results of the stress experienced surfaces in personal adjustment. Medical Protection (2018) surveyed some 600 physicians. A mental health problem was reported by $85 \%$ ( $75 \%$ stress, $49 \%$ anxiety, and 36\% reported diminished self-esteem). Just under one third $(32 \%)$ had exhibited depression during their medical career, and one-in-eight expressed suicidal feelings. There was a reluctance to discuss these issues with anyone $(40 \%)$ and a quarter (24\%) expressed a stigma attached to mental health issues. As the possible sources of stress which impacted on mental health, they indicated excessive workload, long working hours, regulation and scrutiny, and negligence claims. These findings are consistent with those in another UK study, involving close to 2000 doctors. Cohen et al. (2016) reported that $60 \%$ of doctors had experienced symptoms coupled with mental illness. The major obstacle hindering disclosure were the undesirable feature of being 'labelled' and a lack of understanding of the nature of the support structure. Trainee and young doctors were less likely to be open in expressing their mental health problems.

Stress has also been examined amongst psychotherapists with similar results. They displayed most extreme stress through extensive insurance records, and excessive temporal demands - having scarce time for their personal lives; little spare time (Petrowski et al. 2014). Just over a quarter exhibited stress due to financial concerns. Others stressors included the high degree of responsibility, undue time pressure, or increased workload.

A German survey (Korzilius 2016) involved some 10,000 health practitioners, including physicians and psychotherapists, a high percentage of doctors and psychotherapists (96\% and 99\% respectively) enjoyed their work and this is assumed to be attributable to the self-autonomy of those working in private practice. Conversely, $56 \%$ of doctors reported having too little time for their patients, and almost a third (29\%) expressed a feeling of being "burnt out", clearly indi- 
cating that stress imposed at work is not necessarily related with dissatisfaction. As regards income, $70 \%$ of general practitioners were satisfied with their "payment", more so that the specialists (64\%). Overall, twothirds of doctors were satisfied with their financial situation. Psychotherapists were currently significantly less satisfied with their income (45\%). And when reporting over their overall financial situation, less than one half of psychotherapists expressed satisfaction. These findings are consistent with the National Mental Health Survey of Doctors and Medical Students in Australia (Beyondblue 2013). An anonymous survey of 12,252 doctors and 1,811 medical students portrayed the "higher rates of psychological distress... compared to both the Australian population and other Australian professionals" (p. 2) due in large part to the fact that "...general work experience for Australian doctors is stressful and demanding" (p. 4). A salient point amongst doctors was the "greater degree of resilience to the negative impacts of poor mental health" (p. 5). Moreover, Mata, Ramos and Bansal (2015) reviewed 31 cross-sectional and 23 longitudinal studies involving 17,560 resident physicians in training. The overall prevalence of depression or depressive symptoms was $28.8 \%$. It has long been recognised that development of depression has been associated with a higher risk of future depressive episodes and increased long-term morbidity, hence these findings are likely to influence the long-term health of resident doctors. It has been argued that depression among doctors may also affect patients, given established associations between physician depression and lower-quality care.

\section{DEPRESSION AND BURNOUT}

In part the prevalence of depression is an outcome of the mental and physical exhaustion (O'Connor et al. 2018) and may lead to the reluctance to seek treatment, partly because it might jeopardize their license to practice. Suicidal ideation was reported by $6.3 \%$ of 7905 surgeons (Shanafelt et al. 2011). Only $26 \%$ of surgeons with recent suicidal ideation had sought assistance (p. 54) mainly over concerns that it might influence their right to practise. Elliot, Tan and Norris (2010) examined 86 studies in a systematic review of mental health among doctors. They also reported that (a) there were barriers to seeking help; and (b) that "...more hours of sleep, greater job satisfaction, higher income, lower stress at work... were negatively correlated with depression" (p. 5). Additional reasons for burnout and reluctance to seek treatments may relate in part to the training of health professionals. Indeed, Montgomery (2014) emphasised that:

...physicians are educated to be clinicians first, and their role as a leader, team member, or manager is secondary... this disconnect between their training/ expectations and the realities of the need to work with co-workers and patients who have different visions of how the organisation (hospital) should operate means that job burnout is inevitable (p. 54).
For mental health professionals, in particular, an increased workload and high caseloads were linked with mental and physical exhaustion from 62 studies that were reviewed (O'Connor et al. 2018). The overriding conclusion from the studies reviewed is that depression and anxiety is prevalent through stressors in the provision of health services. This appears to be inherent in the organisation of health services, the structure of the professions involved and the nature of the processes that characterise modern health care. Whilst Montgomery (2014) was pessimistic that a cure for burnout might be found, an alternative approach that originates form the slow medicine movement may offer some partial relief.

\section{SLOW MEDICINE AS A PANACEA FOR STRESS AND BURNOUT IN MODERN HEALTH CARE}

In an editorial on slow medicine, Bauer (2008) contrasted the high-tech approach of fast medicine with its over-use of resources with slow medicine that takes:

"...slow gentle measures, even to do nothing rather than something aggressive and expensive in the face of doubt... Costs of care can be lowered by making choices to wait before rushing into something unwise or uncertain, and by putting into proper place the role of the outside expert, facility, or machine. By being heard, related to, and cared for, patients will be more satisfied"

Slow medicine is a heterogeneous approach that includes technology and rapid response where this is required but for the most part it contrasts with the demands of an accelerated pace of worklife, omnipresent digital contact, and the palpable lack of time for personal connection, reflection, insight or mindfulness in bureaucratised and managerial health care settings. Kirkcaldy et al. (2009) characterised one aspect of this through the damaging time aspects of our Western society. They distinguished between time and punctuality.

Time-bound societies have a competitive attitude towards time, and their view fast is better. Hence, their emphasis is upon fast-living, fast-eating and fast-tempo, manic type work behaviour that focuses upon 'catching up' and not being 'left behind'. Whereas time-bound societies view time as a linear process, those who are timeblind see it as cyclical. Time-bound societies centre around clocks, schedules, delivery dates, agendas, and urgent deadlines, all of which can make for serious misunderstandings in the workplace ... Just as nations may differ in their pace of life, so organisations are likely to display their own speed of functioning. The desire to control speed and efficiency of work processes may lead to deteriorations in working climate and health (pp. 305-306).

Slow medicine is broader but neither simplistic nor holistic in its diagnosis, especially with respect to psychological health. As an example, Lown (1999) discussed the psychological problems that are comorbid or overshadow an illness: 
"... as is commonly the case, the general physician often diagnoses psychoneurosis, a wastebasket term to which are consigned a host of conditions lacking scientific explanations. The patient is seriously shortchanged by this dismissal of the psychological aspects of illness, and ignoring the emotional dimension lessens a doctor's capacity to ameliorate a chronic illness. Drugs may improve some of the presenting symptoms for a time, but the underlying illness is not healed. Inattention to the psychological domain fractures medicine at its heart by divorcing cure from healing"

Livingston (2006) evidences aspects of a slower medicine approach when he recalled a typical problem of a patient who had seen diverse psychiatrists over time and consumed an array of medication who problems included:

"anxiety, depression, attention deficit disorder, insomia, sleep apnoea, and narcolepsy' ... taking antidepressants and anti-anxiety agents ... methamphetamine for an acute depressive disorder and hypnotic medicine to help him sleep. He had surgery on his soft palate to help with snoring and was hooked up to a positive pressure machine every night to insure that he didn't stop breathing in his sleep. He wasn't much interested in psychotherapy ... This does not deny that medication is frequently invaluable to help people deal with mental illness ... medicines can also help temporarily with problems in living: situational anxiety, grief, posttraumatic stress. But when the only thing psychiatrists do for people is medicate them for their intrapsychic discomforts, we have sacrificed something essential in our professional identities ... I prefer to challenge people to relinquish passivity, stop waiting for answers outside themselves, mobilise their courage and determination, and try and discover what changes will bring them closer to others and to the people they want to be" (2006, p. 41).

Lown (1999) noted that patients have turned medicine into repair:

"what are essentially tears in the social fabric wrought by violence, economic oppression, class ostracism, racism, sexism, and a host of other factors. In a consumer culture ... medicalization is the response to mounting social frustrations. Dissatisfaction with one's job or marriage or children, or with one's lot if life, are not uncommonly somaticised. Most doctors do not have the time, patience, training, or incentives to become involved in these societal quagmires, and their inattention leads patients to shop around for a quick fix".

\section{CONCLUSION}

Whilst advances in health care have lowered disease and reduced mortality the price for this fast medicine has been at the expense of individualised treatment and the welfare of the health professional. The concerns about the adequacy of health care about complex changes in health administration being at times counter- productive are evident. This scoping review has also highlighted how modern health care is detrimental for the well-being of the purveyors of medicine and allied health services. The managerial demands imposed on mental health services are but one example of the pervasive stressors that stretch human capabilities to provide effective treatment to all fairly and equally. In addition to the inadequacies of health care is the stress and burnout that was described. This has led to depressive and anxiety symptoms, a reluctance to seek help and a situation with few obvious answers. The role of slow medicine is not a panacea nor a band-aid approach but a fundamental slowing and redirection of health care form a managerial to a medical emphasis.

\section{Acknowledgements: None.}

\section{Conflict of interest: None to declare.}

\section{Contribution of individual authors:}

Bruce Kirkcaldy made substantial contributions to conception and design of this review, and also participated in revising it and giving the final approval of the version to be submitted.

James Athanasou was involved in literature searches and drafting the article.

\section{References}

1. Allard E, Legault A \& Genet C: Dignity or dignities? When a concept has multiple meanings. Journal of Pain and Symptom Management 2018; 56:e1-e2

2. Bauer J: Slow Medicine. Journal of Complementary and Alternative Medicine 2008; 14:891-892

3. Behrens R: Parliamentary and Health Service Ombudsman. Maintaining momentum: driving improvements in mental health care. Ordered by the House of Commons, 19th March, 2018

4. Beyondblue: National mental health survey of doctors and medical students. 2013; Sydney: www. beyondblue.org.au

5. Cohen D, Winstanley SJ \& Greene G: Understanding doctors attitude towards self-disclosure of mental illhealth. Occupational Medicine 2016; 66:383-389

6. Cylus J, Papanicolas I, Smith PC: Health system efficiency. How to make measurement matter for policy and management 2016; London: WHO Regional Office Copenhagen

7. Eliacin J, Coffing JM, Matthias $M$ et al.: The relationship between race, patient activation, and working alliance: Implications for patient engagement in mental health care. Administration and Policy in Mental Health and Mental Health Services Research 2018; 45:186-192

8. Elliot L, Tan J \& Norris S: The mental health of doctors. A systematic literature review 2010. Downloaded on 5th June 2018 from

http://resources.beyondblue.org.au/prism/file?token $=B L / 0823$

9. Epstein R: What's the opposite of burnout? Journal of General Internal Medicine 2017; 32:723-4

10. Felton $A$ \& Stickley T: Rethinking risk: a narrative approach, The Journal of Mental Health Training, Education and Practice 2018; 13: 54-62 
11. Fleischer AB: Disciplinary foundations: Activities therapies. In W.H. Reid \& S.B. Silver (Eds.), Handbook of mental health administration and management pp192-205. New York, Taylor and Francis, 2003

12. Hamel $G$ \& Zanini M: What we learned about bureaucracy from 7,000 HBR readers. Harvard Business Review 2017; 2-9

13. Hederos K, Jantti M, Lindahl L \& Torssander J: Trends in life expectancy by income and the role of specific causes of death. Economica 2017; 85:605-625

14. Hill G: Consultants critical of NHS managerialism and bureaucracy in new report. 2015. https://www.dundee.ac.uk/ news/2015/consultants-critical-of-nhs-managerialism-andbureaucracy-in-new-report.php

15. Korzilius H: Ärzte Umfrage. Grosse Zufriedenheit trotz hoher Belastung. Deutsches Ärzteblatt 2016, 113:43

16. Javanparast S, Maddern J, Baum F, et al.: Change management in an environment of ongoing primary health care system reform: A case study of Australian primary health care services. International Journal of Health Planning and Management 2018; 33:e67-e88

17. Kirkcaldy BD, Athanasou $J$ \& Trimpop $R$ : The idiosyncratic construction of stress: examples from medical work settings. Stress Medicine 2000; 16:315-326

18. Kirkcaldy BD, Furnham A \& Shephard RJ: The impact of working hours and working patterns on physical and psychological health. In Cooper, C.L. and Cartwright, S. (Eds.) The Oxford handbook of organisational health (305-306). Oxford: Oxford University Press, 2009

19. Leape LL: Error in medicine. Journal of the American Medical Association 1994; 272:1851-1857
20. Livingstone G: And never stop dancing. Thirty more true things you need to know now. New York: Marlow and Company, 2006

21. Lown B: The lost art of healing. Practicing compassion in medicine. New York: Random House, 1999

22. Mata DA, Ramos MA \& Bansal N: Prevalence of Depression and Depressive Symptoms Among Resident Physicians A Systematic Review and Meta-analysis. Journal of the American Medical Association 2015; 314:2373-2383

23. Medical Protection: Mental health and doctors. What you need to know. 2018.

https://www.medicalprotection.org/uk/help-advice/mentalhealth-and-doctors-what-do-you-need-to-know

24. Montgomery A: The inevitability of physician burnout: Implications for interventions. Burnout Research 2014; 1:50-56

25. O'Connor K, Neff DM \& Pitman S: Burnout in mental health professionals: A systematic review and metaanalysis of prevalence and determinants. European Psychiatry 2018 ; http://dx.doi.org/10.1016/j.eurpsy.2018.06.003

26. Petrowski K, Hessel A, Brähler E \& Eichenberg C: Occupational stressors in practicing psychological psychotherapists. Health 2014; 6:378-386

27. Shanafelt TD et al.: Special report: suicidal ideation among American surgeons. Archives of Surgery 2011; 146:54-62

28. Sweet V: Slow medicine. The way to healing. New York: Riverhead Books, 2017

Correspondence:

Bruce Kirkcaldy, MD

International Centre for the Study of Occupational and Mental Health

Dusseldorf, Germany

E-mail: brucedavidkirkcaldy@yahoo.de 